\title{
Application of PBL Can Improve the Teaching Quality of Professional Degree Graduate Students in Hepatobiliary Surgery
}

\author{
Hao Tang, J. S. Ming, Yong Chen* \\ Hepatobiliary Surgery, The First Affiliated Hospital of Chongqing Medical University, Chongqing, China \\ Email: *chenyong61@126.com
}

How to cite this paper: Tang, H., Ming, J. S., \& Chen, Y. (2020). Application of PBL Can Improve the Teaching Quality of Professional Degree Graduate Students in Hepatobiliary Surgery. Creative Education, 11, 2609-2616.

https://doi.org/10.4236/ce.2020.1112193

Received: November 10, 2020

Accepted: December 12, 2020

Published: December 15, 2020

Copyright $\odot 2020$ by author(s) and Scientific Research Publishing Inc. This work is licensed under the Creative Commons Attribution International License (CC BY 4.0).

http://creativecommons.org/licenses/by/4.0/

\section{(c) (i) Open Access}

\begin{abstract}
Objective: To explore the application effect of problem-based learning (PBL) teaching in standardized training, which is designed to train professional degree graduate students in hepatobiliary surgery. Methods: A total of 60 graduate students with professional degrees admitted to our hospital for hepatobiliary surgery in 2017-2018 were selected as research objects. The trainees were randomly divided into problem-based learning (PBL) group and lecture-based learning (LBL) group, and the training effects of the two groups were observed at the same time. Results: After the training is completed, compared with the LBL group, the PBL group students' final exam scores, skill scores, and the students' scientific research ability, clinical ability, organization ability, thesis ability, collaboration ability, and language ability have been significantly improved $(P<0.05)$. Conclusion: The application of PBL teaching can effectively improve the teaching quality of clinical degree postgraduate standardized training.
\end{abstract}

\section{Keywords}

Problem-Based Learning, Hepatobiliary Surgery, Professional Degree Graduate Student

\section{Introduction}

Professional physician is the ultimate goal of professional degree education of clinical medicine. Therefore, education focuses on the cultivation of clinical ability, requiring graduate students to systematically master the professional theoretical knowledge of the subject, and master the clinical skills of the subject, and improve the ability to analyze and solve problems in clinical work (Burgess, Ayton, \& Mellis, 2016). 
In recent years, professional postgraduates have become the main subject of postgraduate enrollment in major teaching medical center (Neville, Norman, \& White, 2019). In addition, hepatobiliary surgery diseases are common diseases, often accompanied by huge potential risks (Benson, D'Angelica, Abbott, Abrams, \& Darlow, 2019). The simple teaching mode of textbook explanation and slide explanation can no longer satisfy the clinical and teaching work of hepatobiliary surgery, and it is difficult for the students to enhance the initiative of learning and the proficiency of knowledge.

Problem-based learning (PBL) is a new teaching concept developed at McMaster University by Barrows and Tamblyn in the 1960s (Donner \& Bickley, 1993). And it is a constructivist, student-centered teaching philosophy (Donner \& Bickley, 1993; Hendry, Lyon, Prosser, \& Sze, 2006). In addition, PBL is designed to assist retention and application of knowledge while developing the skills desired in medical students, such as clinical interpretation, critical judgment, and self directed learning (Miles, Kellett, \& Leinster, 2017; Kinkade, 2005). The implementation of PBL is often centered on clinical or research issues, and students cooperate, discuss and learn independently in groups (Grisham, Negin, Martiniuk, \& Wright, 2015). So as to master the learning content, train the problemsolving ability, cultivate the students' creativity, divergent thinking, and cultivate the students' social skills and teamwork skills (Ford, 2005; Neve, Bull, Lloyd, Gilbert, \& Mattick, 2017).

In 2017-2018, we have applied PBL to improve the teaching quality of professional degree graduate students in hepatobiliary surgery, as follows.

\section{Method}

\subsection{Participants}

In total 60 professional degree graduate students were selected as the research trainees. Randomly divided into 30 in the LBL group and 30 in the PBL group. They are all graduate students with a professional degree in hepatobiliary surgery admitted from 2017 to 2018. And filter into the group according to the following criteria. Entry criteria: 1) The trainees are professional degree graduate students admitted in 2017-2018. 2) Before being selected, the trainees had no hospital work experience except for internships. 3) Trainees can independently complete satisfaction evaluation. Exclusion criteria: 1) Those who have difficulty expressing themselves. 2) Those who are emotionally volatile. 3) Those PBL training courses absent $>10 \%$ of the students. There was no significant difference between the experimental group and the control group in age, gender, and entrance scores.

\subsection{Course Content}

LBL group: The assistant instructors would teach participants the anatomy, physiology and clinical skills of hepatobiliary surgery in stages according to the teaching plan, and guided the trainees to inquire medical history, physical ex- 
amination, and medical record writing. The trainees summarized and analyzed the characteristics of the medical history, put forward diagnostic opinions, and formulated treatment plans, then supplemented and summarized by instructors.

PBL group: The assistant instructors divided all the participants into several groups and announced the next lecture one week in advance. Trainees in groups were encouraged to inquire and collect relevant information in major databases and the teaching platform. The students in the group need to divide the work, collaborate, synthesize, discuss, then summarize the opinions of the group, and finally report to the lecturer.

\subsection{PBL Curriculum Applications}

Before the start of the course, the instructor will collect clinical pictures and data of various cases, record surgical videos, and establish a specialist picture library and surgical video library. Establish a unique picture and surgical video database, electronic teaching materials, and online teaching platform for hepatobiliary surgery.

Different from LBL, trainees in the PBL group need to take different forms of assessment according to the content of the course, such as: 1) Skills competition: Students need to complete physical examinations and common skills operations within the specified time, such as debridement and dressing, puncture and drainage. Then experienced professors will score and evaluate the performance of each student. 2) Participants give academic lectures: Hepatocellular carcinoma, biliary stones, pancreatic cancer and other diseases will be explained in the form of PPT by group participants. The team members need to consult the information and make a summary, so as to produce PPT and on-site explanation. According to the exquisite production of the PPT and the language expression, the group will be evaluated by postgraduates and teachers, and the final score will be calculated based on $50 \%$ of the two. This format can also be used for online meetings, with the help of various meeting platforms or live broadcast platforms, which is especially suitable in special times. 3) Frequently Asked Questions: Acute abdominal pain, upper gastrointestinal bleeding and other difficult diseases will be first learned by the students. Difficult questions can be raised on the network platform and answered by the instructor in turn. Common problems will be collected and summarized, and will be explained by the lecturer in the class. 4) Final defense: After the lecture, each group selects topics to conduct an overview, such as the latest research and diagnosis and treatment progress of a certain disease. Part of the tutors of the course will serve as judges, and will be graded based on the selection of the postgraduate's defense, expression ability, accuracy and credibility of the review.

\subsection{Date Collection}

The scientific research ability, clinical thinking ability, organization and management ability, literature review ability, collaboration ability and language ex- 
pression ability demonstrated by the trainees in the course will be evaluated by the instructor by the integral quantitative method as a comprehensive score. The scientific research ability, clinical thinking ability, organization and management ability, literature review ability, collaboration ability, language expression ability demonstrated by the students in the course will be evaluated by the instructor by the integral quantitative method as a comprehensive score. Abdominal physical examination, dressing change and suture removal, debridement, surgical area disinfection and draping, abscess incision and drainage, three-chamber two-capsular tube hemostasis, abdominal puncture, and cardiopulmonary resuscitation will be selected as the operation test items, and the students will be randomly selected. The exam is scored based on a total score of 100 points. The final scores of professional degree graduate students are weighted and added by theoretical examination scores (50\%), skills scores (30\%), and comprehensive scores (20\%). The final scores of professional degree graduate students are weighted and added by theoretical examination scores (50\%), skills scores (30\%), and comprehensive scores (20\%). The results of the experimental group and the control group will be statistically analyzed. At the same time, stratified cluster random sampling is used, and students are randomly selected to conduct a satisfaction questionnaire survey. The questionnaire includes the stimulation of learning interest, the cultivation of self-learning ability, the ability to analyze and solve clinical problems, the ability to consult databases, and the ability to express language. The results were analyzed by SPSS25.0 software.

\subsection{Date Analysis}

In order to determine the difference between the two groups, descriptive data analysis used SPSS statistical software for statistical processing. $P<0.05$ was considered statistically significant.

\section{Results}

Before you begin to format your paper, first write and save the content as a separate text file. Keep your text and graphic files separate until after the text has been formatted and styled. Do not use hard tabs, and limit use of hard returns to only one return at the end of a paragraph. Do not add any kind of pagination anywhere in the paper. Do not number text heads-the template will do that for you.

Finally, complete content and organizational editing before formatting. Please take note of the following items when proofreading spelling and grammar:

In the PBL teaching group, the test score is $(90.3 \pm 5.0)$, the operation score is ( $92.6 \pm 5.5)$, and the comprehensive score of scientific research ability, clinical ability, and organization ability is $(85.0 \pm 8.0)$. The theoretical test score of the LBL teaching group is $(85.2 \pm 7.1)$, the operational test score is $(86.4 \pm 8.0)$, and the comprehensive score of scientific research ability, clinical ability, and organization ability is $(73.0 \pm 9.1)$. The performance of PBL teaching group was sig- 
nificantly better than that of LBL teaching group $(83.1 \pm 3.5$ VS $90.0 \pm 3.1, P<$ 0.05 ) (Table 1). At the same time, the satisfaction of the PBL group was significantly higher than that of the LBL group (83.33\% VS 63.33\%, Table 2).

\section{Discussion}

\subsection{Advantages and Applications of PBL}

Traditional teaching (LBL) focuses on the understanding and recitation of medical theoretical knowledge (Liu, Ouyang, Wang, Chen, \& Jiang, 2020). Unlike the PBL teaching method, which focuses on multiple learning approaches and problem-solving, its purpose is to guide students in self-study and enhance their independent thinking and problem-solving abilities. Compared with the traditional teaching method of LBL, PBL has incomparable advantages (Cohen-Schotanus, Muijtjens, Schönrock-Adema, Geertsma, \& Vleuten, 2010).

Many medical schools internationally are actively developing PBL courses, and PBL has been widely recognized. Tais F. Galvao et al. developed PBL teaching in pharmacy (Galvao, Silva, Neiva, Ribeiro, \& Pereira, 2014). They found that compared with traditional teaching methods, PBL could help students think and solve practical problems better and encourage them to learn independently during their careers. In addition, the study concluded that PBL students have better academic performance. In addition, a randomized controlled trial by ChunXiao Liu et al. showed that the teaching method of PBL + LBL combines the advantages of the two (Liu, Ouyang, Wang, Chen, \& Jiang, 2020). While achieving systematization and methodology, the use of innovative methods could significantly improve teaching efficiency. PBL combined with LBL was an effective way to cultivate personnels. But they also pointed out that in most schools, PBL was not the most common teaching method, but only as a supplementary teaching method to LBL. There was no standardization in PBL, and there was no standardized teaching material and question library (Lehrer, Murray, Benzar, Stormont, Lightfoot, Hafertepe et al., 2015; Huang, Zheng, Li, Li, \& Yu, 2013).

However, PBL students have high learning enthusiasm, active thinking, and

Table 1. Comparison of the final scores of the two clinical postgraduates.

\begin{tabular}{ccccc}
\hline Group & Theoretical test scores & Operation test scores & Consolidated results & overall rating \\
\hline PBL Group & $90.3 \pm 5.0$ & $92.6 \pm 5.5$ & $85.0 \pm 8.0$ & $90.0 \pm 3.1$ \\
LBL Group & $85.2 \pm 7.1$ & $86.4 \pm 8.0$ & $73.0 \pm 9.1$ & $83.1 \pm 3.5$ \\
P & $<0.001$ & $<0.001$ & $<0.001$ & $<0.001$ \\
\hline
\end{tabular}

Table 2. Two groups of student satisfaction feedback survey results (\%).

\begin{tabular}{cccc}
\hline Group & satisfaction & general & Not satisfied \\
\hline PBLGroup & 83.33 & 10.0 & 6.67 \\
LBLGroup & 63.33 & 23.33 & 13.33 \\
P & $<0.001$ & $<0.001$ & $<0.001$ \\
\hline
\end{tabular}


the learning atmosphere is obviously better than traditional teaching method. This change from passive to active learning also made the instructors aware of the drawbacks of traditional teaching and the necessity of teaching reform (Ford, 2005). The analysis of this research results can show that the application of PBL teaching in the postgraduate education of hepatobiliary surgery can effectively improve the comprehensive learning ability of students. At the same time, the satisfaction of the trainees has increased significantly, and the trainees are more motivated to participate in clinical learning of hepatobiliary surgery.

\subsection{Issues and Solutions in PBL}

Although our research confirms that the training performance of the PBL group is significantly higher than that of the LBL group $(P<0.05)$, it shows that the recent effect of the PBL teaching method is significant (Matsui, Ishihara, Suganuma, Sato, \& Yoshioka, 2007). There are still some problems in PBL teaching in this research.

For the trainees: 1) The trainees do not have a strong sense of cooperation. Most of them tend to work alone and are not good at communication (Neve, Bull, Lloyd, Gilbert, \& Mattick, 2017). 2) Insufficient access to information. Students mainly obtain information through books or ordinary networks, but professional databases are only used by a few people (Zhang, Wang, Zhang, \& Zou, 2018). 3) The students' learning initiative is insufficient, and some students are still used to traditional passive learning. 4) The lack of time and energy of the trainees. After professional degree graduate students start clinical training, trivial and complicated clinical work will occupy their time and attention (Eucebious, 2010; O'Connor \& Carr, 2012).

Clinical medicine is a practical science. There is no so-called standardized answer in treatment, so that different patients with the same disease may have completely different treatment plans. Instructors should pay attention to helping trainees to actively establish a sense of teamwork and strengthen mutual communication. Instructors and assistants need to establish and improve the database, including picture and video library, multimedia electronic teaching materials, network education platform and WeChat communication platform, etc., to stimulate students' interest in learning, reduce time wasting, and encourage students to focus on key points in "fragmented" time Learning, thereby enhancing the learning effect (Neville, Norman, \& White, 2019; Azer, 2011).

For the instructors: 1) PBL is not widely recognized among instructors (Lehrer, Murray, Benzar, Stormont, Lightfoot, Hafertepe et al., 2015). Therefore, the instructors have a large deviation in their perception of PBL. 2) Due to the lack of a unified standardized teaching material and teaching evaluation system that matches the PBL teaching model, the quality of teaching depends on the experience of the instructor and is unstable (Azer, 2011). 3) Most tutors have insufficient PBL teaching experience and cannot stimulate students' learning enthusiasm (Neve, Bull, Lloyd, Gilbert, \& Mattick, 2017).

In order to utilize the advantages of the PBL teaching, the instructor should 
change traditional concepts, accept innovations, broaden multidisciplinary knowledge, fully understand the essence of PBL teaching, and master the skills. At the same time, the hospital should regularly organize tutors to conduct PBL teaching training and demostration class, so that instructors can correctly grasp the characteristics of PBL teaching, and promote the improvement and development of teachers.

\section{Conclusion}

Our research shows that the application of PBL can effectively improve the shortterm teaching quality of postgraduates in hepatobiliary surgery. The application prospect of PBL is eye-catching. However, the long-term teaching effect of PBL still needs a larger randomized controlled study. In addition, we concluded that for professional graduate students, LBL should be properly applied in the process of applying PBL. Constantly improve the problem design, educational content, time arrangement, organizational form, and effect evaluation to further improve the teaching effect.

\section{Conflicts of Interest}

The authors declare no conflicts of interest regarding the publication of this paper.

\section{References}

Azer, S. A. (2011). Training Students to Learn in a Problem-Based Learning Programme. Medical Education, 45, 510. https://doi.org/10.1111/j.1365-2923.2011.03952.x

Benson, A. B., D’Angelica, M. I., Abbott, D. E., Abrams, T. A., \& Darlow, S. D. (2019). Guidelines Insights: Hepatobiliary Cancers, Version 2.2019. Journal of the National Comprehensive Cancer Network: JNCCN, 17, 302-310. https://doi.org/10.6004/jnccn.2019.0019

Burgess, A., Ayton, T., \& Mellis, C. (2016). Implementation of Team-Based Learning in Year 1 of a PBL Based Medical Program: A Pilot Study. BMC Medical Education, 16, 49. https://doi.org/10.1186/s12909-016-0550-3

Cohen-Schotanus, J., Muijtjens, A. M. M., Schönrock-Adema, J., Geertsma, J., \& Vleuten, C. P. M. V. D. (2010). Effects of Conventional and Problem-Based Learning on Clinical and General Competencies and Career Development. Medical Education, 42, 256-265. https://doi.org/10.1111/j.1365-2923.2007.02959.x

Donner, R. S., \& Bickley, H. (1993). Problem-Based Learning in American Medical Education: An Overview. Bulletin of the Medical Library Association, 81, 294-298.

Eucebious, L. M. (2010). Facilitation in Problem-Based Learning: Experiencing the Locus of Control. Nurse Education Today, 30, 638-642. https://doi.org/10.1016/j.nedt.2009.12.017

Ford, J. C. (2005). Influence of a Problem-Based Learning Curriculum on the Selection of Pathology as a Career: Evidence from the Canadian Match of 1993-2004. Human Pathology, 36, 600-604. https://doi.org/10.1016/j.humpath.2005.04.003

Galvao, T. F., Silva, M. T., Neiva, C. S., Ribeiro, L. M., \& Pereira, M. G. (2014). ProblemBased Learning in Pharmaceutical Education: A Systematic Review and Meta-Analysis. The Scientific World Journal, 2014, Article ID: 578382. 
https://doi.org/10.1155/2014/578382

Grisham, J. W., Negin, J., Martiniuk, A. L., \& Wright, E. (2015). Problem-Based Learning (PBL) and Public Health: An Initial Exploration of Perceptions of PBL in Vietnam. Asia-Pacific Journal of Public Health, 27, NP2019-NP2027. https://doi.org/10.1177/1010539512436875

Hendry, G. D., Lyon, P. M., Prosser, M., \& Sze, D. (2006). Conceptions of Problem-Based Learning: The Perspectives of Students Entering a Problem-Based Medical Program. $\mathrm{Me}$ dical Teacher, 28, 573-575. https://doi.org/10.1080/01421590600878150

Huang, B. L., Zheng, L. W., Li, C. J., Li, L., \& Yu, H. Y. (2013). Effectiveness of ProblemBased Learning in Chinese Dental Education: A Meta-Analysis. Journal of Dental Education, 77, 377-383. https://doi.org/10.1002/j.0022-0337.2013.77.3.tb05482.x

Kinkade, S. (2005). A Snapshot of the Status of Problem-Based Learning in U.S. Medical Schools, 2003-04. Academic Medicine Journal of the Association of American Medical Colleges, 80, 300-301. https://doi.org/10.1097/00001888-200503000-00021

Lehrer, M. D., Murray, S., Benzar, R., Stormont, R., Lightfoot, M., Hafertepe, M. et al. (2015). Peer-Led Problem-Based Learning in Interprofessional Education of Health Professions Students. Medical Education Online, 20, Article ID: 28851.

https://doi.org/10.3402/meo.v20.28851

Liu, C. X., Ouyang, W. W., Wang, X. W., Chen, D., \& Jiang, Z. L. (2020). Comparing Hybrid Problem-Based and Lecture Learning (PBL + LBL) with LBL Pedagogy on Clinical Curriculum Learning for Medical Students in China: A Meta-Analysis of Randomized Controlled Trials. Medicine, 99, e19687. https://doi.org/10.1097/MD.0000000000019687

Matsui, K., Ishihara, S., Suganuma, T., Sato, Y., \& Yoshioka, T. (2007). Characteristics of Medical School Graduates Who Underwent Problem-Based Learning. Annals of the Academy of Medicine of Singapore, 36, 67-71.

Miles, S., Kellett, J., \& Leinster, S. J. (2017). Medical Graduates' Preparedness to Practice: A Comparison of Undergraduate Medical School Training. BMC Medical Education, 17, 33. https://doi.org/10.1186/s12909-017-0859-6

Neve, H., Bull, S., Lloyd, H., Gilbert, K., \& Mattick, K. (2017). Evaluation of an Innovative, Evidence-Guided, PBL Approach. Clinical Teacher, 15, 156-162. https://doi.org/10.1111/tct.12656

Neville, A., Norman, G., \& White, R. (2019). McMaster at 50: Lessons Learned from Five Decades of PBL. Advances in Health Sciences Education: Theory and Practice, 24, 853863. https://doi.org/10.1007/s10459-019-09908-2

O’Connor, J., \& Carr, A. (2012). Problem-Based Learning in Guyana: A Nursing Education Experiment. International Nursing Review, 59, 376-379. https://doi.org/10.1111/j.1466-7657.2011.00959.x

Zhang, S., Xu, J., Wang, H., Zhang, D., \& Zou, L. (2018). Effects of Problem-Based Learning in Chinese Radiology Education: A Systematic Review and Meta-Analysis. Medicine, 97, e0069. https://doi.org/10.1097/MD.0000000000010069 